\title{
PARECERES.
}

\section{Aplicação de penalidade fiscal sem observância dos princípios do processo - Nulidade de Procedimento Fiscal.}

\author{
Geraldo Ataliba \\ Professor livre docente de Direito Finan. \\ ceiro na Faculdade de Direito da Universi- \\ dade de São Paulo.
}

Parecer.

Submete-nos o professor Canuto Mendes de Almeida o incluso estudo, de sua autoria, pedindo o nosso parecer sobre a tese nele sustentada.

O fulcro de toda a questão está em se determinar qual a correta interpretação da disposição do art. 189 do regulamento do I.P.I. (decreto $61.514,12-10-1967$ )

Em síntese, sustenta - com rigor exegético e extrema acuidade jurídica - esse mestre da Faculdade de São Francisco, que o dispositivo regulamentar mencionado absolutamente não autoriza autuação por sonegação (de tributos) ou prática de ilícitos administrativo-penais.

Estas, somente podem ser objeto de autuação mediante efetiva e cabal apuração e prova da prática de fato determinado, circunstanciadamente descrito - com a devida comprovação das condições de tempo e lugar em que se deram - e juridicamente qualificado.

Em outras palavras: as punições administrativo-penais só podem ser impostas depois de provado que determinada pessoa, em dia determinado, praticou tal ou qual ato (que deve ser descrito), infringindo tal ou qual norma jurídica (capitulação) e, pois, incidindo nas sanções respec. tivas. 
Assim se redige o mandamento objeto precípuo deste estudo:

"Constituem elementos subsidiários, para o cálculo da produção e correspondente pagamento do imposto, dos estabelecimentos industriais, o valor e quantidade das matérias-primas, produtos intermediários e embalagens adquiridos e empregados na industrialização e acondicionamento dos produtos, o valor das despesas gerais efetivamente feitas, o da mão-de-obra empregada e o dos demais componentes do custo de produção, assim como as variações dos estoques de matérias-primas, produtos intermediários e embalagens".

O exato significado desta disposição - é a opinião do professor CANUTO, da qual compartilhamos pelos seus científicos fundamentos e pelas razões neste parecer expostas - está em ditar critérios para o lançamento de ofício e procedimento de autuação por auto-lançamento inexato (quanto a certas circunstâncias de fato)

Estabelece critérios para correção de auto-lançamento, com base no custo da produção, mediante o levantamento de elementos subsidiários técnica que passou a ser necessária, quando da adoção da sistemática de imposição ad-valorem relativamente ao imposto de consumo (agora batizado de imposto sobre produtos industrializados - I.P.I.).

\section{Considerações Propedêuticas.}

Importa interpretar o art. 189 do regulamento do I.P.I., para determinação de seu alcance, função e significado. É importante verificar se ele tem a finalidade de derrogar os princípios do processo da aplicação das sanções administrativo-penais, consagrados pelo nosso direito tributário - em consonância com os mais altos e fundamentais postulados do nosso regime - ou se outro é o seu sentido.

Porque o fisco tem entendido que esta disposição autoriza a punição de infrações presumidas, ou seja, independentemente de prova do processo próprio.

A correta inteligência desta disposição não pode ser alcançada pela simples leitura de seu teor, isoladamente considerado. A exegese jurídica 
jamais pode ser aplicada a um mandamento só, com abstração do conjunto do qual é ele parte.

Não é possível entender o texto, sem inseri-lo no contexto do qual faz parte.

Só a interpretação sistemática de todo o regulamento, com a apreensão de seus princípios informadores pode conduzir à correta exegese de cada um de seus mandamentos. MaXimiliano - o sumo expositor, entre nós, da ciência hermenêutica — bem demonstrou a indispensabilidade da interpretação sistemática.

A perplexidade ou o êrro resultam de exame superficial ou apressado, que não leve em consideração o caráter unitário do direito, sua feição sistemática e a harmonia ínsita à sua estrutura.

Este regulamento não é um amontoado ilógico e dispar de mandamentos desconexos e independentes recíprocamente. Por instância própria da dogmática jurídica 9 exigência universal e primeira da ciência do direito, é um conjunto uno, coeso e harmônico de disposições normativas.

E um conjunto harmonioso de disposições coordenadas entre si, hierarquicamente dispostas, sistematicamente organizadas, de forma a erigir uma unidade estruturada em tôrno de alguns princípios básicos, informadas por uma coerência interna que coordena e solidariza cada qual de suas partes, entre si relacionadas, pelos traços comuns de vinculação formal ao mesmo sistema e fidelidade e subordinação aos princípios informativos do todo em que se inserem.

Daí porque não ser possível interpretar isoladamente o art. 189 ou qualquer outro mandamento deste regulamento - como toda e qualquer norma jurídica.

Efetivamente, nenhuma norma jurídica paira avulsa, como que no ar. Nenhum mandamento jurídico existe em si, como que vagando no espaço, sem escôro ou apoio Não há comando isolado ou ordem avulsa. Porque estes - é propedêutico - ou fazem parte de um sistema, nele encontrando seus fundamentos, ou não existem juridicamente.

Efetivamente, toda norma jurídica faz parte de um sistema; já surge numa determinada posição dentro do sistema, nele se integra e com as demais partes se artícula harmoniosamente, relacionando-se com seus 
princípios e com todas as suas conseqüências e decorrências - já que os princípios (isto é axiomático) postulam exigências indeclináveis, inafastáveis.

Sistema é um conjunto ordenado e sistemático de normas, construido em função de objetivos socialmente consagrados.

KeLSEN ensina que "todas as normas de uma determinada ordenação jurídica são criadas segundo as disposições de outras normas, até que se chegue à norma fundamental, a qual constitui a unidade do sistema de normas, a unidade de toda a ordenação jurídica" (Teoria Generale del diritto e dello stato, p. 126) E enfatisa: "A unidade do fundamento último de validade constitui a unidade do sistema normativo" (op.cit., p. 405)

Aliás, a própria noção filosófica de sistema é no que se trata sempre de "uma multiplicidade de elementos articulados segundo uma idéia de totalidade" (Walter Brugger, s.j Diccionário de filosofia, Herder, Barcelona, 1953, p. 360)

O conceituado jusfilósofo mexicano Juan Manuel Teran - ao expor o caráter unitário e sistemático de toda ordenação jurídica - bem sublinha que "sistema é um conjunto ordenado de elementos, segundo uma perspectiva unitária” (Filosofia del derecho, p. 146)

Quanto ao axioma que sustenta a feição sistemática do direito, dispensa demonstração, não só pelo princípio da proibição do "regressum ad infinitum", como pelo seu universal acatamento, precisamente como axioma.

É oportuno, a propósito, encerrar estas considerações, recordando clássica lição de Ferrara, quando assinala que "um princípio jurídico não existe isolado, mas acha-se em íntima conexão com outros princípios. O direito objetivo, de fato, não é um aglomerado caótico de disposições, mas um organismo jurídico, um sistema de preceitos coordenados e subordinados, no qual cada um deles tem um lugar próprio" "Assim, todo princípio forma o membro de um grande todo. Dessa conexão recebe luz a norma particular $O$ sentido de uma disposição ressalta nítido e preciso, quando é ela confrontada com outras normas gerais ou supraordenadas, de que constitui uma derivação, uma aplicação ou uma exceção, quando se remonta, dos preceitos singulares, ao inteiro ordenamento jurídico. 
Aplicadas estas considerações ao problema em exame, verificamos a imperiosa necessidade de harmonização do art. 189 com o sistema formado pela legislação do I.P.I., e com a própria ordenação jurídica total, da qual este é parte. Bem evidente, também, fica a impossibilidade do interpretação deste dispositivo, sem antes relacioná-lo devidamente com os que lhe são sistematicamente ligados.

Nesta ordem de idéias cabe, pois, colocar algumas questões que se sugerem como decorrência imediata e natural das premissas lançadas: que são elementos subsidiários? Para que existem, em que hipóteses cabe deles cogitar? Como e quando se deve a eles recorrer?

As respostas serão sugeridas naturalmente, pela exposição que se segue.

Técnica de Incidência do I.P.I.

Sucessor do impôsto chamado "de consumo" e substancialmente idêntica a ele, o I.P.I. incide juridicamente sobre a produção, e econômicamente sobre o consumo.

A lei the define o fato gerador como consistindo na "saída do produto do estabelecimento industrial" (art. $7^{\circ}$, III do R.I.P.I.)

E que, embora se tratando de oneração tributária dos produtos, e sendo necessário colhê-los quando encerrada a produção - a partir da consideração de que tudo que se produz se destina a ser consumido escolhe-se como momento ficto do término do processo de produção (por sua comodidade e objetividade) a saída do produto do estabelecimento que o produziu.

Verificado este fato instantâneo - a saída do produto - nasce a obrigação tributária, que tem por objeto o pagamento do tributo em causa (I.P.I.)

A apuração do fato, porém, em suas características subjetivas e objetivas, com a consequiente determinação do sujeito passivo, bem como das circunstâncias de lugar, tempo e modo, depende de um ato ulterior - momento lógico insuprimível, como o diz GranNini - que deve tudo isto verificar e consignar formalmente.

Tal ato é o que, no Brasil, adotamos designar por lançamento (accertamento, no direito italiano). 
Lançamento do I.P.I.

Diz o regulamento do I.P.I. que este imposto "é lançado, pelo contribuinte" (sic), "na nota fiscal" (art. 24, inciso II, do decreto federal 61.514 de 12 de outubro de 1967, regulamento do I.P.I., vigente), sob sua exclusiva responsabilidade (art. 26)

O preparo da operação de lançamento - a que se refere o art. 24 - consiste "na descrição da operação que the dá origem, na discriminação e classificação fiscal do produto. ., no cálculo do imposto devido e no registro do seu valor, em parcela própria do documento fiscal em que é feito" (art. 25) - no caso, nota fiscal.

Esta "operação" complexa, efetuada pelo contribuinte, "sob sua exclusiva responsabilidade" (art. 26), é, na verdade, ato preparatório do lançamento - mas não lançamento propriamente dito, como se poderia apressadamente concluir, da leitura dos termos em que vazado o regulamento.

Esta colaboração do contribuinte constitui-se em ato importante, imprescindível, "sine qua non", mas de natureza meramente preparatória; é que, como muito bem o salienta a doutrina, o lançamento é ato administrativo e, portanto, de exclusiva competência dos órgãos da administração pública. Aliás, o código tributário nacional, no seu art. 142, é claro e explícito ao dispor que:

"Compete privativamente à autoridade administrativa constituir o crédito tributário pelo lançamento, assim entendido o procedimento administrativo tendente a verificar a ocorrência do fato gerador da obrigação correspondente, determinar a matéria tributável, calcular o montante do tributo devido, identificar o sujeito passivo e, sendo caso, propor a aplicação da penalidade cabível".

É costume classificar-se o lançamento do I.P.I. como auto-lançamento, dando ensejo a entender-se, errôneamente, que o próprio contribuinte pratica este ato administrativo. $\mathrm{Na}$ verdade, trata-se de equívoco, uma vez que, como visto - por se tratar de ato administrativo - é sempre privativo da autoridade fiscal. 
É clássica a lição de RUBens Gomes De Sousa, muito difundida entre nós e cuja autoridade se impôs de forma definitiva e inquestionável: “. o lançamento é ato administrativo unilateral. é sempre efetuado pela autoridade fiscal e somente por ela..." (Estudos..., p. 41).

Este vício é conseqüência do estado empírico dos estudos de direito tributário, até recente período. Nele, entretanto, não incidiu o código tributário nacional, quando the atribui, corretamente, a designação do "lançamento por homologação" (art. 150), que é uma forma de expressar a idéia de lançamento sujeito a homologação.

E bem claro o dispositivo legal invocado, ao sublinhar que este opera-se pelo ato em que a referida autoridade, tomando conhecimento da atividade assim exercida pelo obrigado, expressamente a homologa".

Dada a especial natureza de imposto indireto - característica do I.P.I. - depois de praticada esta operação preparatória, pelo contribuinte, fica a autoridade fiscal no dever de homologá-la, desde que rigorosamente obedecida a legislação vigente e verificada a perfeita regularidade dos atos preparatórios, para, então, ser efetuado, completado, consumado o lançamento, mediante a homologação dos cálculos e atos do contribuinte. Homologação, segundo a melhor doutrina "é o ato administrativo unilateral, vinculado, de contrôle de outro ato jurídico, pelo qual se the dá eficácia ou se afirma a sua validade" (O.A. BANDEIRA DE Mello, Princípios gerais de direito administrativo, p. 509).

Da combinação deste conceito com aquele próprio do lançamento, se vê que o lançamento só se consuma, só se exaure juridicamente, com a sua homologação pelo fisco. Só é eficaz e só tem sua validade afirmada administrativamente, depois de "controlado" pela autoridade fiscal.

Do que se vê que esta, precisa de refazer os cálculos, rever as estimações do contribuinte, reavaliar todos os elementos objetivos que con. dicionaram a operação praticada pelo contribuinte, para então confirmá-lo, validá-lo, ou negar-lhe a sua validade, proclamando sua ineficácia.

Como entretanto, se trata de "um momento insopprimibile nello svolgimento del rapporto d'imposta" (GIANNINI, I concetti fondamentali del diritto tributario, -p. 271), deve nesta última hipótese, o fisco, proceder a novo lançamento - o que fará de acordo com os critérios da lei, para ter validade e, em conseqüência, eficácia. 
$\mathrm{Na}$ hipótese de o contribuinte omitir-se na prática deste ato - ou praticá-lo em desacordo com o regulamento, — a "autoridade administrativa efetuará, de ofício o lançamento, mediante a instauração do processo fiscal", (art. 27), obedecidos os critérios constantes da lei.

Para a prática dos atos preparatórios do lançamento, de que tratam os artigos 24 a 29 do regulamento, deve o contribuinte - e, à sua falta, a autoridade fiscal - como visto (art. 25), classificar o produto tributado, na forma dos arts. 17 e 18 e, em seguida, proceder ao cálculo do imposto (arts. 19 a 23)

No caso da consulta, a classificação do produto não oferece qualquer problema. Estudemos, portanto, o problema do cálculo do imposto, que se dá "mediante aplicação das alícotas constantes da tabela, sobre o valor tributável dos produtos" (art.19).

O conceito de valor tributável é de vital importância para a compreensão da legislação do I.P.I. e, sobretudo, para a sua correta aplicação. A lei erige em regra geral - para determinação do valor tributável - "o preço da operação de que decorreu o fato gerador, incluídas todas as despesas acessórias, debitadas ao comprador ou destinatário" (art. 20, III)

Dada, entretanto, a possibilidade de fluidez do "preço da operação", bem como a possibilidade da concorrência de inúmeros fatores que possam retirar a objetividade deste critério, a própria lei vem estabelecer critérios presuntivos, traçando um teto mínimo insuperável para este "valor tributável" (art. 21), que "não poderá ser inferior", "ao preço corrente no mercado atacadista" (inciso I) ou "a $70 \%$ do preço de venda a consumidor, nem ao previsto no inciso anterior" (inciso II) - nos casos de remessa de produto para estabelecimento do próprio contribuinte, ou para estabelecimento interdependente, ou ainda para posto de venda a varejo no próprio estabelecimento que industrializou o produto.

Da leitura do regulamento se vê que a determinação destes tetos mínimos decorre da possibilidade de o preço da operação poder ser acertado, entre os particulares, de acordo com critérios que não os comuns, normais e gerais.

Por outras palavras: a lei, erigindo o preço da operação em critério para determinação do valor tributável dos produtos industrializados, previu a hipótese da saída da mercadoria do estabelecimento produtor, 
com preço inferior aos comuns e correntes do mercado - em virtude de esta saída poder ser determinada por operações cujos preços não obedeçam à previsão da própria regra geral — qual seja: a de transferência da propriedade da mercadoria, com finalidade de lucro.

Daí porque estabeleceu que o valor tributável teria este teto mínimo, a fim de evitar tanto economia de imposto, quanto, mesmo, fraudes e outros expedientes, tendentes a burlar o critério do valor tributável, em detrimento da arrecadação.

Como as hipóteses do art. 21 não esgotam os casos que escapam à regra geral do inciso III do art. 20 , veio a disposição do art. 22 , do regulamento, prever a possibilidade de operações em que os produtos fossem transferidos sem que esta (a operação jurídica) se enquadrasse nas hipóteses do art. 21 e sem que o critério econômico geral do valor tributável pudesse ser aplicado. Tal é a razão da disposição do art. 22 do regulamento, assim redigida:

"Se a saída do produto, do estabelecimento industrial ou equiparado a industrial, se der a título de locação ou decorrer de operação realizada a título gratuito, assim considerada também aquele que, em virtude de não transferir a propriedade do produto, não importe em fixar-lhe o preço, o imposto será calculado sobre o valor tributável definitivo nos incisos do artigo anterior, observadas as hipóteses neles previstas".

Desta forma, ainda mesmo as operações "a título gratuito" ou "a título de locação" - inclusive qualquer operação que "en virtude de não transferir a propriedade do produto, não importe em fixar-lhe o preço" - vêm expressamente contempladas, pelo regulamento, de modo a não permitir a frustração do critério econômico do valor tributável, estabelecido como regra geral pelo art. 19

Destarte, toda e qualquer saída de mercadoria, configurada do fato gerador do I.P.I., terá um critério legal de determinação do seu valor tributável - que será o preço ou qualquer dos critérios subsidiários, adotados pela legislação - previstos expressamente, da maneira o mais possível objetiva, assegurando a legalidade da tributação e a objetividade 
dos critérios estabelecidos em defesa dos direitos do contribuinte e dos interesses do fisco (observando critério de rigorosa bilateralidade jurídica).

Ocorrendo, porém, a hipótese de os documentos expedidos pelas partes serem omissos, ou não merecerem fé ou, ainda, quando se dê o caso de operação a título gratuito - em que seja difícil a apuração dos valores previstos nos artigos 19 a 22 - a lei prevê o arbitramento do valor tributável (art. 23), que terá por base o valor real da operação, quando de qualquer forma se possa obtê-lo ( $\S 1 .^{\circ}, 1 .^{\mathrm{a}}$ parte, do art. 23).

Exluída esta hipótese, "o arbitramento tomará por base o preço médio do produto no mercado do domicílio do contribuinte ( $\S 1 .^{\circ}$ do art. 23 ), o preço de venda a consumidor com abatimento de $70 \%$ ( $\$ 2.0^{\circ}$ art. 23), ou, em último caso - e à absoluta falta destes elementos — "o custo industrial do produto, acrescido de todas as parcelas que de acôrdo com as normas deste regulamento, entrarem na formação do valor tributável, inclusive da margem de lucro normal, no ramo do negócio" ( $\$ 3 .^{\circ}$ do art. 23)

Do exposto se verifica que todas as possíveis hipóteses de impedimento - por qualquer razão - da aplicação do critério geral de determinação do valor tributável são expressamente previstas, pelo regulamento do I.P.I.

Desta forma, quer na prática da homologação (art. 26) quer quando se dê hipótese de lançamento de ofício (prevista no art. 27, combinado com o art. 29), dispõe o fisco de todos os critérios para a correta, perfeita e normal determinação do valor tributável.

E se nenhum dos critérios incidentes na norma geral - de determinação do valor tributável (artigos 20 a 22) - puder ser aplicado, pela não verificação das hipóteses previstas, surge (então) a oportunidade do arbitramento (art. 23), observada a escala de precedência estabelecida nos $\S \S$ do art. 23.

No caso da consulta - tendo havido discordância entre a escrituração da consulente e os dados levantados pelo fisco - houve impossibilidade de homologação (dos atos preparatórios de lançamento), pelo fisco, tendo sido instaurado processo fiscal (art. 27), e tendo sido procedido o arbitramento, com base no "custo industrial do produto", a que se refere o $\S 3 .^{\circ}$ do art. 23 . 
Ocorrendo esta hipótese - como de fato ocorreu, no caso em estudo - como deverá agir a autoridade fiscal? Como arbitrar o valor tributável a que se refere o art. 19 do regulamento, tendo por base o custo industrial do produto?

Pode, nesta matéria, agir arbitrariamente a autoridade fiscal?

Em verificado o caso previsto pela lei, aqui, fica o fisco entregue ao próprio critério? É livre de lançar mão dos elementos que entenda oportunos ou convenientes de serem utilizados?

A resposta é clara e intuitiva: também nesta hipótese - que vem rigorosamente prevista no regulamento - os critérios a serem observados (para o lançamento de ofício) vêm rigorosamente descritos e indicados na lei, de forma a afastar qualquer margem de arbítrio.

Do dever de fiscalização como rotina e expediente de controle dos auto-lançamentos.

O dever de fiscalização, incumbente aos "órgãos regionais" do D.R.I., pelos "seus agentes fiscalizadores" (art. 171, § 1. ${ }^{\circ}$ ), nas "jurisdições" e "seções" fiscais ( $\S 2 .^{\circ}$ ), consiste no acompanhamento e controle das atividades tributáveis dos contribuintes, no interêsse da arrecadação.

Pode até a competência da fiscalização prorrogar-se além dos limites das "jurisdições" e "seções" previstas na lei "desde que se trate de prosseguir ou concluir levantamento de débito. .iniciado, à vista de prova ou indícios positivos de falta de pagamento do imposto" (art. 172, caput).

Dentre as providências decorrentes da existência de indícios de falta de pagamento, é relevante o "levantamento dos elementos subsidiários referidos no art. 189" (inciso II do art. 172).

Esta providência, entre outras, tem a finalidade - como se dessume do exame sistemático do regulamento, bem como do próprio teor das disposições normativas referentes à fiscalização - de habilitar o fisco a controlar (para homologar) os lançamentos dos contribuintes, ou permitir o levantamento dos elementos tendentes a informar os lançamentos de ofício. 
Pois, uma das formas de avaliação dos elementos do fato gerador - avaliação tendente a informar o lançamento de ofício - é prevista especialmente no art. 189 do R.I.P.I. Corresponde à última das hipóteses consideradas pelo regulamento, para critério de lançamento.

É o cálculo do imposto com base no custo da produção.

Se todos os critérios legais anteriores não puderem ter aplicação, então, o fisco - principalmente tendo em vista o lançamento de ofício - deverá recorrer ao "levantamento dos elementos subsidiários, referidos no art. 189" (inciso II, do art. 172).

Em outras palavras: se pelos critérios dos arts. 21 e 22, não fôr possível fazer-se o levantamento de ofício - ou homologar-se o "auto-lançamento" - resta o critério da estimação e arbitramento do debitum tributário, pelo cálculo do custo da produção (de que cuida o art. 189).

Outro não é o sentido da disposição do $\S 3 .^{\circ}$ do art. 23 , quando, ao cuidar do arbitramento, impõe que este tome "por base o custo indusdustrial do produto"

"Na falta ou dificuldade de apuração dos preços de que trata este artigo, o arbitramento tomará por base o custo industrial do produto, acrescido de todas as parcelas que, de acordo com as normas deste Regula. mento, entrarem $\mathrm{na}_{\mathrm{a}}$ formação do valor tributável, inclusive da margem de lucro normal no ramo de negócio"

Pois, o art. 189 se coordena com esta disposição, ao completá-la, dizendo como determinar-se o volume ou montante desta produção e qual seu custo.

Munidos destes critérios, os agentes fiscais poderão levantar os elementos subsidiários, determinar o volume da produção, estimar o valor de suas parcelas e arbitrar o tributo devido.

Tudo isto feito, poderão, na forma da lei, os agentes fiscais proceder com correção e segurança ao lançamento de ofício, a que se refere o art. 27

Do que se vê que o sentido desta disposição - sistematicamente interpretada - é autorizar a correta apuração do débito tributário in concretu e jamais a aplicação de punições administrativo-penais. Entender que, usando das atribuições conferidas pelo art. 189, o fisco pode 
presumir a prática de fraudes e, em consequiência, aplicar as penalidades correspondentes, repugna não só aos princípios gerais do direito e ao senso jurídico, como à técnica da repressão às infrações fiscais e, sobretudo, à letra e ao espírito do sistema legal brasileiro, vigente (especialmente o regulamento do I.P.I., como visto)

A aplicação de penalidades administrativo-penais, como a aplicação de sanções em geral deve ser precedida de processo, na forma da lei

Explicada a função da disposição do art. 189, tal como rigorosamente contida no contexto sistemático do regulamento do I.P.I. - como instrumento normal de contraste das atividades tributáveis dos contribuintes - vê-se a inaplicabilidade da mesma disposição à matéria de penalidades ou sanções administrativo-penais.

Estas, de acordo com a sistemática adotada por este regulamento - em harmonia com os princípios que regem todo o nosso sistema jurídico - somente podem ser aplicadas mediante o devido processo legal, como no próprio regulamento se vê.

Assim é que, para "apuração de infrações, no regulamento" existe "processo contencioso" (art. 192), que "terá por base o auto ou a representação" (art. 194)

Esta peça (auto de infração), base do processo fiscal, é importantíssima, pela sua função no contraditório, sem o qual é nulo o processo. Porisso deve conter o relato minucioso da "infração, das circunstâncias qualificativas e agravantes existentes. e tudo mais que. sirva para esclarecer os fatos objeto do procedimento" (art. 197)

É o libelo, circunstanciado e minucioso, que, após a ciência regular do acusado, produz o efeito jurídico de basear o processo, mediante a instauração válida da instância processual, na esfera administrativa.

Porisso, o auto é "submetido à assinatura do autuado" (se pessoa física de seu representante legal (se pessoa jurídica), os quais entretanto podem negar-se a assiná-lo ( $\S 10^{\circ}$ do art. 198 ), sem que isto acarrete agravação de falta argüida ( $\S 10^{\circ}$, parte final, art. 198)

Nesta hipótese, não há ainda contraditório juridicamente configurado (note-se que é do nosso direito constitucional o contraditório, nulos sendo os processos nos quais ele não se verifique regularmente) 
Deve, então o processo ser preparado - para ser válido, para não ser nulo - mediante as intimações (art. 204, I) ulterior visto (conhecimento do processo pelos acusados) e recebimento da defesa (II e $\mathrm{V}$ do art. 204)

A inobservância destas formalidades rigorosas - principalmente a intimação inicial dos acusados ( $\S 10^{\circ}$ do art. 207) — é condição de validade do processo. Sem isto, ele será nulo e as penalidades não poderão ser aplicadas.

Este paralelismo - observado pela legislação do I.P.I. - relativamente ao processo judicial, paralelismo obrigatório para qualquer outro procedimento administrativo, resulta do imperativo jurídico inarredável da observância do princípio do contraditório, toda vez que se cuida da aplicação, a qualquer pessoa, da gravames pessoais ou patrimoniais, a título de sanção legal.

É que "no direito pátrio está implícita, entre as garantias constitucionais, a do chamado "due process of law" (art. 150, $\S 35$ da Constituição Federal). Deste modo, também entre nós, ninguém será privado da vida, da liberdade ou da propriedade, sem o devido processo legal" (J. Frederico Marques, "garantia do due process of law no direito tributário", in R.D.P n. ${ }^{\circ}$ 5, p. 28)

E entendimento incontroverso, no Brasil, que sem processo legal nulos são os atos que importem restrição ou perda de direitos (cf. SANthiago Dantas, in Problemas do direito positivo, 1953, Rio, p. 37 e segs.)

Segundo o direito brasileiro, "na esfera administrativa o processo legal tem de ser atendido, em virtude das imediatas restrições à vida financeira do administrado que a multa acaba por constituir e criar" (FREDERICO MARQUES, op.cit., p. 29) "Seguem_se, neste caso, vias análogas às do procedimento judicial, através de atos de comunicação procedimental destinados a estabelecer a bilateralidade no processo administrativo, para que, assim, fiquem entendimentos os princípios básicos do "due process of law" O administrado toma ciência dos fatos em que a administração alicerça sua pretensão e o exercício da autotutela. E defende-se, dentro dos limites que a lei traça, para que, assim, não periclite o seu direito de defesa" (op.cit., p. 29)

Qual é, relativamente às infrações ao R.I.P.I., o devido processo legal? Responde FREDERICo MARQUES, com sua inconteste autoridade de 
publicista e processualista: "Convém frisar que, em princípio, pois, o auto lavrável no serviço externo - e a representação — lavrável no serviço interno - constituem ainda atos específicos de início do procedimento fiscal" (op.cit. p. 30).

A legislação do I.P.I. obediente a todos estes princípios prevê, como assinalado, o comportamento dos agentes fiscais, em tema de apuração de infrações e sua repressão - mediante a aplicação das sanções legais.

Não obstante não esteja em vigor o código de processo tributário (ou lei orgânica), de autoria de Gilberto DE UlhoA CANTo, não se pode dizer que não haja um direito processual tributário brasileiro.

Mesmo que não houvesse leis, os princípios deveriam ser aplicados. $E$ do nosso regime que o patrimônio deve ser reguardado. Trata-se, aliás, de garantia constitucional inscrita, entre os direitos individuais arrolados pelo art. 150 da Constituição. Só pode ser perdida a propriedade, parcial ou totalmente, na forma da lei. Ao direito de exigir tributos, conferido ao poder público, se contrapõe o dever de fazê-lo na forma da lei. Outra não é a colocação de Hensel - eminentíssimo vulto do direito tributário alemão - quando define o direito tributário e sublinha o estatuto de garantia constitucional em que se constitui. Tal é também o sentido da formulação sintética do magistral TrotaBAS, ao descrever os cânones do "estatuto do contribuinte".

Por isso JÉze, pai da moderna ciência do direito financeiro na França, ressalta o aspecto fundamental "des trois manches de la partie que se joue entre le fisc et le contribuable".

A ação administrativa é, por definição, infra-legal. Ora, a ação fiscal é ação administrativa: como tal, submetida ao princípio da relação de administração, tal como exposto pelo insigne RUY CIRNe LiMA (Princípios).

Temos, portanto, um processo tributário para todos os tributos, no direito brasileiro, atualmente. Sem dúvida alguma, o mais perfeito de quantos conhecemos é aquele referente ao imposto de produtos industrializados, minucioso na disciplina da seriação de atos que formam o procedimento tendente ao lançamento tributário. São normas de tutela dos direitos do contribuinte, inseridos naquilo que Trotabas chamou de "es- 
tatuto do contribuinte" Fazem parte, segundo lição de José Frederico MARQues do "law of the land", inseridos que são na cláusula "due process of law".

O processo do regulamento do impôsto de renda é imperfeito e incompleto. Mas, os princípios essenciais podem perfeitamente ser encontrados, devendo, quando a hipótese o exigir, ser desdobrados em todas as consequiências que se constituam exigências fundamentais do sistema constitucional.

O processo tributário é semelhante ao processo penal, principalmente naquilo que diz respeito à aplicação de penalidades, sejam elas quais forem (civis, administrativas, administrativo-penais) Desta forma, é o contraditório essencial conforme vimos na lição de Fernando Henrique Mendes de AlmeIda (Nulidade de processo fiscal. ., in R.D.P n. ${ }^{\circ}$, p. 119)

E unânime a doutrina em proclamar a aplicabilidade das normas de direito processual penal e civil ao direito tributário, enquanto não surjam as normas próprias, objeto de lei especial.

E que "as autoridades financeiras são vinculadas à norma jurídica . Não podem, portanto, pretender aquilo que não esteja previsto expressamente na lei; de outra forma, ter-se-ia uma violação das obrigações de ofício" (Giannini, ap.cit., p. 275)

A defesa do patrimônio é o critério fundamental do regime jurídico tributário.

"Principalmente no direito tributário, é verdadeiramente necessária uma tutela amplamente disposta. Trata-se - na imposição dos tributos - do mais importante direito de intervenção do Estado no patrimônio dos seus súditos" (GIanNinI, op.cit., p. 274)

Porisso “. .torna-se necessário revestir a posição jurídica do contribuinte com instrumentos de tutela e defesa, diante do Estado" (GianNINI, p. 375), o que a ordem jurídica assegura pelo processo (administrativo ou judicial)

Temos, no Brasil, a consagração legislativa de todos os ensinamentos da doutrina e do bom senso. Aqui, como na Itália, "o processo tributário é dominado pelo princípio geral do contraditório, que se constitui no meio mais eficaz para a procura da verdade e que o próprio legislador - preocupado com tal exigência lógica de justiça - expressa- 
mente, previu em algumas disposições, como quando estabeleceu que, salvo o caso de explícito consentimento do representante fiscal, não possam ser tomados em consideração documentos, recursos ou réplicas que não tenham sido submetidos aos trâmites burocráticos apropriados, ou não tenham sido exibidos na secretária das finanças 5 dias antes da primeira audiência... (RoToNDI, op.cit., p. 211).

Em conclusão .

Podemos, pois, concluir, respondendo às questões levantadas, extraindo as devidas consequiências do que foi afirmado:

1 Que são elementos subsidiários?

- São aqueles conducentes ao cálculo da produção, com base no seu custo.

2. Para que existem?

- Para a hipótese de o fisco, por qualquer razão, não poder valer-se - como critério para homologação, ou para o lançamento de ofício - do preço da operação que determinou a saída do produto.

3. Em que hipóteses cabe cogitar dos elementos subsidiários?

- Na hipótese prevista no $\S 3 .^{\circ}$ do art. 23 do R.I.P.I.: quando, à "falta ou dificuldade de apuração dos preços "se deva procéder a "arbitramento com base no custo industrial do produto" . "acrescido de todas as parcelas que, de acordo com as normas deste regulamento, entrarem na formação do valor tributável..."

4 O "arbitramento" a que se refere o $\S 3 .^{\circ}$ do art. 23 pode ser arbitrariamente procedido?

— Não há arbítrio em matéria administrativa, e menos ainda tributária. 
O fisco deve obedecer, para proceder ao arbitramento, aos critérios do regulamento e, especialmente, à regra do art. 189

5. Apurada divergência entre a escrituração do contribuinte e os resultados do levantamento fiscal, pode o fisco presumir a prática de fraudes e ilícitos e puni-la?

- Diante desta divergência o fisco deve valer-se dos "elementos subsidiários" para cálculo do imposto devido. Se nisso encontrar indício de fraude, é obrigado a instaurar o procedimento fiscal apropriado, na forma da lei, respeitado o princípio do contencioso, para mediante cabal prova de irregularidades e prática, pelo contribuinte, de atos devidamente capitulados - vale dizer: juridicamente qualificados - aplicar as sanções legalmente previstas.

Em síntese: divergências entre contribuinte e fisco não configuram ilícito administrativo-penal.

Só há punição, no Brasil, desta natureza, mediante processo em que se prove fatos legalmente previstos como ilícitos.

Logo, com fundamento no art. 189 do R.I.P.I., o fisco não pode presumir ilícitos e puni-los.

E o parecer, s.m.j. 